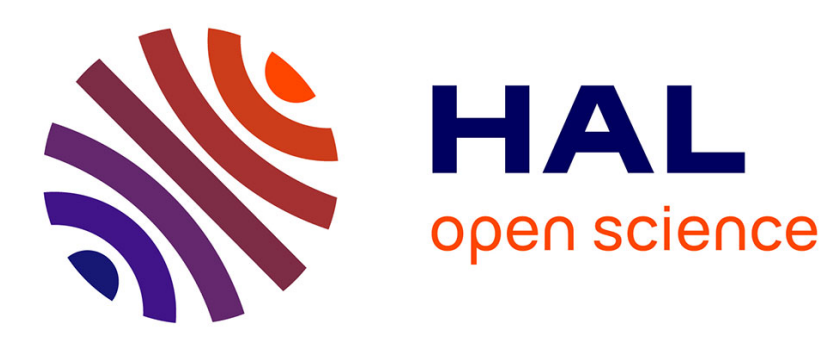

\title{
Optimum plasma grid bias for a negative hydrogen ion source operation with Cs
}

\author{
M. Bacal, Mamiko Sasao, Motoi Wada, Roy Mcadams
}

\section{To cite this version:}

M. Bacal, Mamiko Sasao, Motoi Wada, Roy Mcadams. Optimum plasma grid bias for a negative hydrogen ion source operation with Cs. Review of Scientific Instruments, 2016, 87 (2), pp.02B132. 10.1063/1.4935007 . hal-01305018

\section{HAL Id: hal-01305018 \\ https://hal.sorbonne-universite.fr/hal-01305018}

Submitted on 20 Apr 2016

HAL is a multi-disciplinary open access archive for the deposit and dissemination of scientific research documents, whether they are published or not. The documents may come from teaching and research institutions in France or abroad, or from public or private research centers.
L'archive ouverte pluridisciplinaire $\mathbf{H A L}$, est destinée au dépôt et à la diffusion de documents scientifiques de niveau recherche, publiés ou non, émanant des établissements d'enseignement et de recherche français ou étrangers, des laboratoires publics ou privés. 


\section{AIP | Review of \\ Scientific Instruments}

Optimum plasma grid bias for a negative hydrogen ion source operation with Cs

Marthe Bacal, Mamiko Sasao, Motoi Wada, and Roy McAdams

Citation: Review of Scientific Instruments 87, 02B132 (2016); doi: 10.1063/1.4935007

View online: http://dx.doi.org/10.1063/1.4935007

View Table of Contents: http://scitation.aip.org/content/aip/journal/rsi/87/2?ver=pdfcov

Published by the AIP Publishing

\section{Articles you may be interested in}

Optimization of plasma parameters with magnetic filter field and pressure to maximize $\mathrm{H}$ - ion density in a negative hydrogen ion source

Rev. Sci. Instrum. 87, 02B136 (2016); 10.1063/1.4935230

Cesium dynamics in long pulse operation of negative hydrogen ion sources for fusiona)

Rev. Sci. Instrum. 83, 02B110 (2012); 10.1063/1.3670347

Plasma diagnostic tools for optimizing negative hydrogen ion sources

Rev. Sci. Instrum. 77, 03A516 (2006); 10.1063/1.2165769

Effects of bias potential upon $\mathrm{H}$ - density near a plasma grid of a negative ion source

Rev. Sci. Instrum. 77, 03 A513 (2006); 10.1063/1.2165573

Surface production dominating Cs-free $\mathrm{H}$ - ion source for high intensity and high energy proton accelerators Rev. Sci. Instrum. 75, 1714 (2004); 10.1063/1.1699459

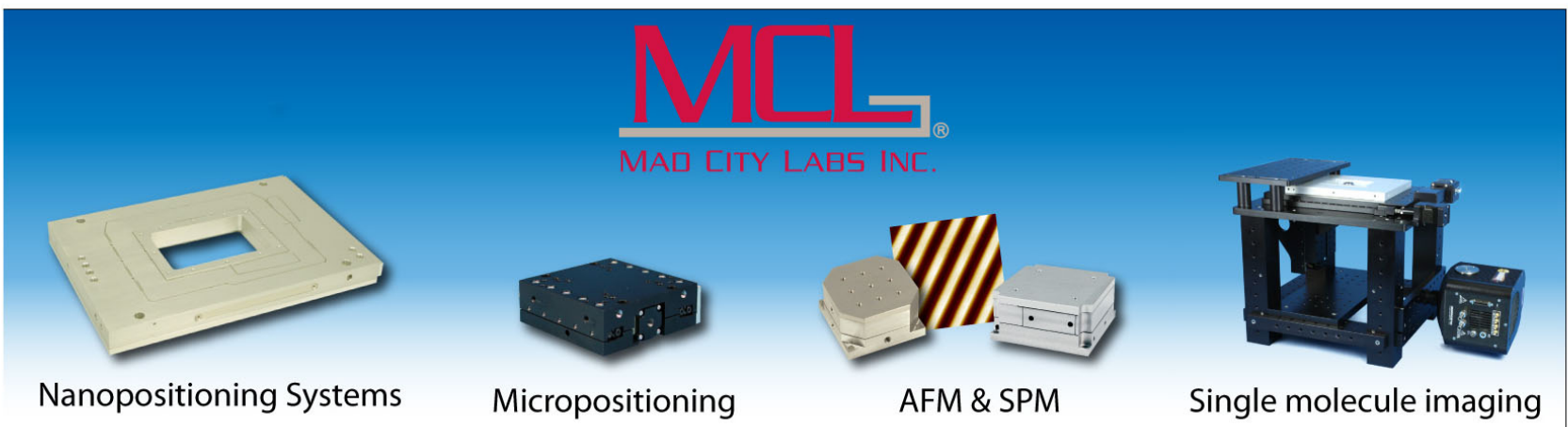




\title{
Optimum plasma grid bias for a negative hydrogen ion source operation with Cs
}

\author{
Marthe Bacal, ${ }^{1, a)}$ Mamiko Sasao, ${ }^{2}$ Motoi Wada, ${ }^{3}$ and Roy McAdams ${ }^{4}$ \\ ${ }^{1}$ UPMC, LPP, Ecole Polytechnique, UMR CNRS 7648, Palaiseau, France \\ ${ }^{2} R \mathcal{E} D$ Promotion Organization, Doshisha University, Kamigyoku, Kyoto 602-8580, Japan \\ ${ }^{3}$ School of Science and Engineering, Doshisha University, Kyotonabe, Kyoto 610-0321, Japan \\ ${ }^{4}$ CCFE, Culham Science Center, Abingdon, Oxfordshire OX14 3DB, United Kingdom
}

(Presented 27 August 2015; received 2 September 2015; accepted 17 October 2015; published online 6 November 2015)

The functions of a biased plasma grid of a negative hydrogen $\left(\mathrm{H}^{-}\right)$ion source for both pure volume and Cs seeded operations are reexamined. Proper control of the plasma grid bias in pure volume sources yields: enhancement of the extracted negative ion current, reduction of the co-extracted electron current, flattening of the spatial distribution of plasma potential across the filter magnetic field, change in recycling from hydrogen atomic/molecular ions to atomic/molecular neutrals, and enhanced concentration of $\mathrm{H}^{-}$ions near the plasma grid. These functions are maintained in the sources seeded with Cs with additional direct emission of negative ions under positive ion and neutral hydrogen bombardment onto the plasma electrode. (C) 2015 AIP Publishing LLC. [http://dx.doi.org/10.1063/1.4935007]

\section{INTRODUCTION}

The plasma grid is one of the major components of the negative ion source. The contemporary negative ion source is a magnetic multipole or bucket plasma source operated with, or without Cs. The first bucket plasma source, invented by Limpaecher and MacKenzie, ${ }^{1}$ was a chamber surrounded by confining permanent magnets, aimed to demonstrate the possibility of producing dense, quiescent plasma at low neutral atom density. Ehlers and Leung ${ }^{2}$ at LBL (Berkeley, US) and Holmes $^{3}$ at Culham Laboratory (Abingdon, UK) introduced an electrode, called the plasma grid, which was electrically insulated from other chamber walls and contained the hole to extract ions. Thus, they converted the magnetic multipole plasma source into an ion source. The new electrode is often called a plasma grid when several holes are present on the electrode, as for applications to nuclear fusion research experiments, or simply a plasma electrode (PE), when it contains a single hole, as for fundamental research or accelerator applications.

Figure 1 presents schematically the ion source geometry with a filament cathode discharge. The magnetic multipole ion source is usually a chamber (cylindrical or rectangular) surrounded externally by columns or rows of permanent magnets, arranged to enhance the plasma confinement. One end of the chamber is enclosed by the PE and the extraction system. A plasma is generated in the source by primary electrons emitted from tungsten filaments located in the fieldfree region. A magnetic filter (MF) installed at the center of the

\footnotetext{
Note: Contributed paper, published as part of the Proceedings of the 16th International Conference on Ion Sources, New York, New York, USA, August 2015.

a) Author to whom correspondence should be addressed. Electronic mail: marthe.bacal@1pp.polytechnique.fr
}

chamber divides the volume into a source (S) and an extraction (E) regions. This ion source configuration is designated as a tandem source. A weak magnetic field parallel to the PE is usually present due to the proximity of the magnetic filter, or the magnetic field for electron suppression. RF negative ion sources are also widely used.

\section{ROLES OF THE PLASMA ELECTRODE}

\section{A. Pure volume operation}

\section{1. $\mathrm{H}^{-}$current and co-extracted electron current}

The PE acts as a large Langmuir probe. When a positive bias voltage $\left(V_{\mathrm{b}}\right)$ is applied to the PE with respect to the plasma potential $\left(V_{\mathrm{p}}\right)$ it collects an electron current, while it collects a positive ion current when a negative bias is applied. A positive $V_{\mathrm{b}}$ reduces the electron density $\left(n_{\mathrm{e}}\right)$ in the extraction region and thus, the co-extracted electron current $\left(I^{-}\right)$. Leung et al. ${ }^{4}$ found that in the presence of the magnetic filter a positive bias applied to the PE did not only reduce the co-extracted electron current $\left(I_{\mathrm{e}}\right)$ but also considerably enhanced $I^{-}$as shown in Fig. 2 .

Leung et al. ${ }^{4}$ also reported that the variation of $I^{-}$against $V_{\mathrm{b}}$ depended on the strength of the magnetic filter field; a weak magnetic filter produced a monotonic increase of $I^{-}$followed by saturation, while a stronger magnetic filter field led to a rapid increase of $I^{-}$followed by a rapid decrease, after having attained a maximum at some positive $V_{\mathrm{b}}$ (which is about $+2.5 \mathrm{~V}$ in Fig. 2). Positive $V_{\mathrm{b}}$ monotonically decreased $I_{\mathrm{e}}$, leading to the increase of the ratio $I^{-} / I_{\mathrm{e}}$ at the optimum $V_{\mathrm{b}}$.

Measurements of the $\mathrm{H}^{-}$ion density $\left(n_{-}\right)$by photodetachment and that of the electron density $\left(n_{e}\right)$ by Langmuir probes in a tandem multipole (Camembert II) at Ecole Polytechnique (Palaiseau, France) showed ${ }^{5}$ that a small positive bias of the PE produced a significant increase in the $n_{-}$and a reduction 


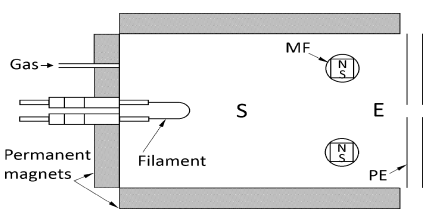

FIG. 1. Schematic representation of a tandem source. S represents the source plasma region, $\mathrm{MF}$ is the magnetic filter, $\mathrm{PE}$ is the plasma electrode, and $\mathrm{E}$ is the extraction region.

of the $n_{e}$ in the extraction region of the source. Figure 3(a) shows the relative negative ion density $n_{-} / n_{e}$ in the extraction region as a function of $V_{\mathrm{b}}$. Note that $n_{-} / n_{e}$ increases with $V_{\mathrm{b}}$ and reaches a maximum of $13 \%$. These results explain the variation of the extracted currents, observed earlier at LBL shown in Fig. 2. Proper arrangement of the filter field and the plasma electrode leads to an extraction region plasma with $n_{-}>n_{e}$ as shown in Fig. 3(b).

The observation at LBL and Ecole Polytechnique that the positive $V_{\mathrm{b}}$ optimizes the extracted $I^{-}$and reduces the co-extracted $I_{e}$ was confirmed by several research groups. It can be noted that in the Culham and Institute of Plasma Physics (IPP) Garching, Germany, sources the positive bias of the PE reduced the electron current, but no enhancement of the negative ion current was obtained. ${ }^{6,7}$ Note that the Culham source is an arc discharge source while the IPP Garching source is an RF source. Thus the reported observation is quite general.

\section{Particle transport across the magnetic filter}

The axial plasma potential $\left(V_{\mathrm{p}}\right)$ profile in Camembert II (Fig. 4) has been measured using a movable Langmuir probe. ${ }^{5}$ The profile at $V_{\mathrm{b}}=0$ indicates that the $V_{\mathrm{p}}$ in the source region is $0.7 \mathrm{~V}$ more positive than that in the extraction region, and $2.7 \mathrm{~V}$ more positive than the walls. On the other hand, the average energy of the $\mathrm{H}^{-}$ions is lower than $0.7 \mathrm{eV}$. Consequently, $\mathrm{H}^{-}$ ions formed in the source (driver) region $\mathrm{S}$ will be trapped

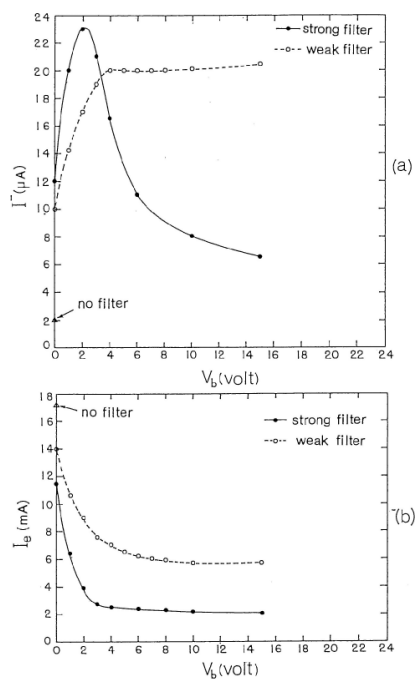

FIG. 2. The dependence on the plasma electrode bias of (a) the extracted $\mathrm{H}^{-}$ current, and (b) the co-extracted electron current. Reprinted with permission from K. N. Leung et al., Rev. Sci. Instrum. 54, 56 (1983). Copyright 1983 AIP Publishing LLC.
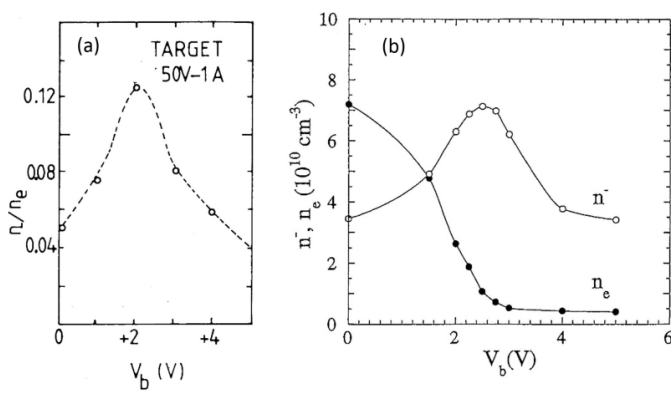

FIG. 3. (a) $\mathrm{H}^{-}$relative density $\mathrm{n}_{-} / \mathrm{n}_{\mathrm{e}}$ in the extraction (target) region of the tandem source. [Reprinted with permission from K. N. Leung and M. Bacal, Rev. Sci. Instrum. 55(3), 338 (1984). Copyright 1984 AIP Publishing LLC.] (b) the electron density $n_{e}$ and negative ion density $n_{-}$at $8 \mathrm{~mm}$ from the plasma electrode in a $50 \mathrm{~V}, 50 \mathrm{~A}$ Camembert III discharge at 3 mTorr. ${ }^{12}$ [Reprinted from F. El Balghiti-Sube et al., Rev. Sci. Instrum. 67(6), 2221 (1996). Copyright 1996 AIP Publishing LLC.]

electrostatically and they cannot escape either to the wall or to the extraction region E. Figure 4 also shows that when the PE is biased $2.5 \mathrm{~V}$ more positive with respect to the anode, only $V_{\mathrm{p}}$ in the extraction region $\mathrm{E}$ increases and the plasma potential gradient across the two regions is substantially reduced. Some of the $\mathrm{H}^{-}$ions in the source region can now traverse across the filter magnetic field into the extraction region, increasing the local $n_{-}$. Note that $n_{-}$in the source region is low, compared to its value in the extraction region. Thus, the PE bias controls the electric field across the magnetic filter and consequently, $\mathrm{H}^{-}$ ions can flow from the source region to the extraction region.

\section{Particle balance in the extraction region}

The extracted $\mathrm{H}^{-}$ion current often shows a peak at the $\mathrm{PE}$ bias slightly above the $V_{\mathrm{p}}$ while $I_{e}$ monotonically decreases by positive PE bias. ${ }^{8}$ The drop of $I_{e}$ corresponds to the reduction of $n_{e}$ by the positive $V_{\mathrm{b}}$ as can be seen in Fig. 3(b). ${ }^{9}$ The depletion of the local electron population requires the other kind of negatively charged particles, $\mathrm{H}^{-}$, to replenish the extraction region to keep space charge neutrality. The $\mathrm{H}^{-}$ions from the bulk plasma replace the depleted electrons in the magnetized extraction region near the PE.

Experimental and theoretical studies on the $\mathrm{H}^{-}$ion transport near the $\mathrm{PE}$ in the extraction region of the $\mathrm{H}^{-}$ sources ${ }^{10-13}$ have revealed the existence of enhanced transport of $\mathrm{H}^{-}$ions toward the extractor correlated to the plasma electrode bias. This is the physical reason for the enhancement

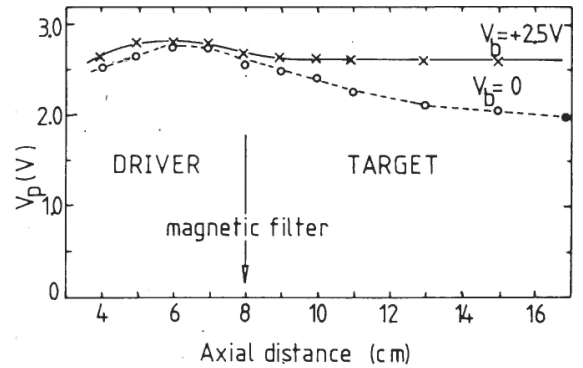

FIG. 4. The axial plasma potential profile in the tandem ion source with two different plasma electrode bias voltages. Reprinted with permission from $\mathrm{K}$. N. Leung and M. Bacal, Rev. Sci. Instrum. 55(3), 338 (2004). Copyright 2004 AIP Publishing LLC. 


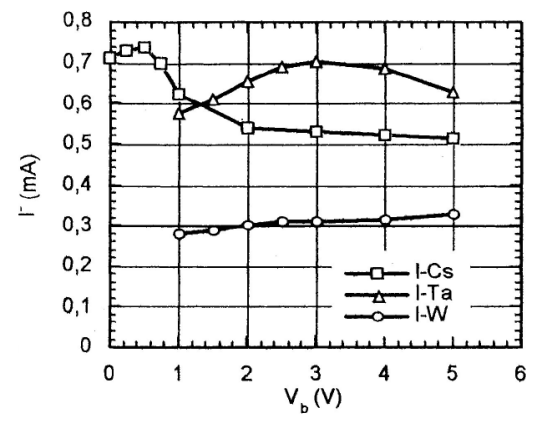

FIG. 5. Dependence of the extracted $\mathrm{H}^{-}$ion current on plasma electrode bias with plasma electrode and walls covered with tantalum, tungsten, and cesium films. Reprinted with permission from M. Bacal et al., Rev. Sci. Instrum. 75(5), 1699 (2004). Copyright 2004 AIP Publishing LLC.

of the $n_{-}$fraction in the extraction region when the PE is biased positive. The effect of the weak transverse magnetic field on $\mathrm{H}^{-}$transport in the ion extraction region was further studied by two-dimensional electrostatic particle simulation models. ${ }^{13,14}$

A collar structure assembled in front of the extractor of an ion source for an accelerator ${ }^{15}$ modifies the electrostatic potential geometry around the extractor. The potential profile interacts with the magnetic filter field to alter the $\mathrm{H}^{-}$transport toward the extraction hole. Note that the plasma electrode of a high power density $\mathrm{H}^{-}$source for an accelerator is not usually biased but electrically connected to the ion source wall.

\section{Particle recycling at the PE surface}

The source (driver) region plasma of the tandem magnetic multicusp source efficiently dissociates molecules and the resulting atoms destroy the $\mathrm{H}^{-}$ion by associative detachment and quench vibrationally excited molecules by vibrationtranslation $(V-T)$ transfer. A suitable choice of the PE material helps solving this problem, by recycling the atomic hydrogen into highly vibrationally excited molecular hydrogen through recombinative desorption processes. The experiments by Hall et al. ${ }^{16}$ have shown that recombinative desorption of hydrogen atoms on both tantalum and tungsten leads to vibrationally excited molecules in levels up to $\mathrm{v}^{\prime \prime}=9$. However, the vibrationally excited molecule populations with $\mathrm{v}^{\prime \prime}>3$ are ten times higher for tantalum than those for tungsten. The experiments at Ecole Polytechnique ${ }^{17}$ showed that the deposition of a fresh tantalum film on the PE and walls of a source with tantalum filaments significantly enhanced the $n_{-}$and the $I^{-}$compared to the same source with tungsten filaments (see Fig. 5).

\section{B. Cs seeded operation}

In some ion sources operated with Cs, like the Kamaboko source in JAERI, surface production on the plasma grid is the dominant mechanism for negative-ion production. ${ }^{18}$ The surface production is more enhanced when the work function of the PE surface is lower. Therefore, it is essential to use the PE with the lowest work function. Tests for choosing the PE mate- rial were effected in the filament-free Kamaboko source, utilizing a microwave $(2.45 \mathrm{GHz})$ discharge. Tests based on measuring the photoelectric current showed that $\mathrm{Cs}$ covered $\mathrm{Ni}, \mathrm{Au}$, and $\mathrm{Ag}$ were the best candidates for the plasma grid material.

Seeding Cs into the ion source modifies the extraction characteristics of $I_{-}$and $I_{\mathrm{e}}$ on PE bias, because of the contribution from direct $\mathrm{H}^{-}$production by positive ion impact on the PE surface, which generates an additional mechanism determining the characteristic for $V_{\mathrm{b}}<V_{\mathrm{p}}\left(\mathrm{V}_{\mathrm{p}}=1 \mathrm{eV}\right) .{ }^{19}$ This can be seen on the results from Camembert III in Fig. 5. Deposition of cesium on the PE enhances $I^{-}$when $V_{\mathrm{b}}$ is negative with respect to $V_{\mathrm{p}}$, as shown in the figure.

\section{CONCLUSION}

The optimum plasma electrode bias has to be discussed depending upon the requirement for the ion source: the bias that gives the maximum $\mathrm{H}^{-}$current, or the bias that suppresses the co-extracted electron current below some limit. The combination of the filter magnetic field and the plasma electrode bias can form the flow of $\mathrm{H}^{-}$ions from the driver to the extraction region. On the other hand, $\mathrm{H}^{-}$ions are supplied from the wall in Cs seeded operation at the bias voltage negative with respect to the plasma potential. This may lead to higher concentration of $\mathrm{H}^{-}$ions in the extraction region, when PE is biased more negatively than $V_{\mathrm{p}}$. Accordingly, the source operation with Cs can be optimized at a plasma electrode bias more negative than the bias that optimizes the operation without Cs.

${ }^{1}$ R. Limpaecher and K. R. Mackenzie, Rev. Sci. Instrum. 44, 726 (1973).

${ }^{2}$ K. W. Ehlers and K. N. Leung, Rev. Sci. Instrum. 50, 1353 (1979).

${ }^{3}$ A. J. T. Holmes, Rev. Sci. Instrum. 53, 1517 (1982).

${ }^{4}$ K. N. Leung, K. W. Ehlers, and M. Bacal, Rev. Sci. Instrum. 54, 56 (1983).

${ }^{5}$ K. N. Leung and M. Bacal, Rev. Sci. Instrum. 55(3), 338 (1984).

${ }^{6}$ A. J. T. Holmes, R. McAdams, G. Proudfoot, S. Cox, E. Surrey, and R. King, Rev. Sci. Instrum. 65, 1153 (1994).

${ }^{7}$ P. Franzen et al., Nucl. Fusion 47, 264-270 (2007).

${ }^{8}$ P. Svarnas, J. Breton, M. Bacal, and R. Faulkner, IEEE Trans. Plasma Sci. 35(4), 1156 (2007).

${ }^{9}$ F. El Balghiti-Sube, F. G. Baksht, and M. Bacal, Rev. Sci. Instrum. 67(6), 2221 (1996).

${ }^{10}$ A. A. Ivanov, A. B. Sionov, F. El Balghiti-Sube, and M. Bacal, Phys. Rev. E 55(1), 956 (1997).

${ }^{11}$ Y. Matsumoto, M. Nishiura, M. Sasao, H. Yamaoka, K. Shinto, and M. Wada, Rev. Sci. Instrum. 79, 02B909 (2008).

${ }^{12}$ H. Takahashi, T. Kasuya, and M. Wada, Rev. Sci. Instrum. 77, 03 A513 (2006).

${ }^{13}$ T. Sakurabayashi, A. Hatayama, and M. Bacal, J. Appl. Phys. 95(8), 3937 (2004).

${ }^{14}$ S. Kuppel, D. Matsushita, A. Hatayama, and M. Bacal, Rev. Sci. Instrum. 81, 02B503 (2010).

${ }^{15}$ K. N. Leung, C. A. Hauck, W. B. Kunkel, and S. R. Walther, Rev. Sci. Instrum. 61, 1110 (1990).

${ }^{16}$ R. I. Hall, I. Cadez, M. Landau, F. Pichou, and C. Scherman, Phys. Rev. Lett. 60, 337-349 (1988).

${ }^{17}$ M. Bacal, A. A. Ivanov, Jr., M. Glass-Maujean, Y. Matsumoto, M. Nishiura, M. Sasao, and M. Wada, Rev. Sci. Instrum. 75(5), 1699 (2004).

${ }^{18}$ M. Kashiwagi, T. Morishita, Y. Okumura, M. Taniguchi, M. Hanada, and K. Watanabe, Rev. Sci. Instrum. 73(2), 964-966 (2002).

${ }^{19} \mathrm{M}$. Bacal, F. El Balghiti-Sube, L. I. Elizarov, and A. Y. Tontegode, Rev. Sci. Instrum. 69(2), 932 (1998). 